\title{
SISTEM INFORMASI PERENCANAAN PENJUALAN DAN DISTRIBUSI BARANG PADA PT GANDUM MAS KENCANA TANGERANG
}

\author{
Jose Josua Sinaga \\ PT Multi Cipta Adikarya, Jakarta, Indonesia \\ e-mail: josejousa30@gmail.com
}

\begin{abstract}
Abstrak
Penelitian ini bertujuan untuk mempermudah para sales man, manager cabang dan data analystt untuk melakukan permintaan hingga penyediaan barang pada pusat-pusat distribusi dengan cara membuat website perencanaan penjualan dan distribusi di PT Gandum Mas Kencana Tangerang. Pembuatan aplikasi ini menggunakan PHP (Hypertext Prepocessor) sebagai bahasa pemrograman dan MySQL sebagai database. Data yang diperlukan didapatkan pada PT Gandum Mas Kencana Tanggerang. Pengumpulan data dilakukan dengan observasi dan wawancara ke lokasi penelitian. Metode yang digunakan dalam pembuatan aplikasi ini adalah metode waterfall. Hasil dari penelitian ini menunjukan bahwa diperlukannya sebuah website untuk membantu sales man, manager cabang dan data analyst dalam melakukan perencanaan penjualan dan distribusi barang. Dan juga mempermudah PT Gandum Mas Kencana Tangerang dalam melakukan pengolahan data dan penyimpanan data.
\end{abstract}

Kata Kunci: Sistem Informasi, Waterfall, PHP, MySQL

\section{INFORMATION SYSTEM ON SALES AND DISTRIBUTION PLANNING OF GOODS IN PT GANDUM MAS KENCANA TANGERANG}

\begin{abstract}
This study aims to make it easier for sales men, branch managers and data analyzers to make requests to supply goods at distribution centers by creating a sales and distribution planning website at PT Gandum Mas Kencana Tangerang. Making this application using PHP (Hypertext Prepocessor) as a programming language and MySQL as a database. The required data is obtained at PT Gandum Mas Kencana Tanggerang. Data collection was carried out by observation and interviews to the research location. The method used in making this application is the waterfall method. The results of this study indicate that a website is needed to assist sales men, branch managers and data analystis in planning sales and distribution of goods. And also make it easier for PT Gandum Mas Kencana Tangerang to perform data processing and data storage.
\end{abstract}

Keywords: Information System, Waterfall, PHP, MySQL

\section{Pendahuluan}

Perkembangan dunia teknologi dan informasi yang semakin pesat setiap perusahaan berusaha menerapkan teknologi sebagai upaya efisiensi biaya [1]. Selain mempermudah dan mempercepat proses komunikasi dan informasi, teknologi informasi juga dimanfaatkan dalam kegiatan bisnis. Bahwa teknologi informasi memperoleh kedekatan antara pebisnis dengan pelanggannya, karena ini mempersingkat jarak dan waktu sehingga akan mengurangi kesenjangan jarak dan waktu permintaan konsumen dan pemenuhan kebutuhannya [2]. Dengan adanya kemajuan teknologi informasi maka kegiatan yang dilakukan manusia bagi perusahaan dikelola secara lebih efektif dan efisien sehingga mendapatkan hal yang maksimal. 
Selama ini PT Gandum Mas Kencana Tangerang (GMK) sudah menerapkan pendekatan Distribution plam saat melakukan distribusi suatu barang. Dengan adanya Distribution plan dapat menciptakan ketersediaan masing-masing jenis dan jumlah stock barang ter-manage secara optimal baik di gudang pabrik dan juga gudang distributor. Penerapan suatu perencanaan yang dilakukan PT GMK tersebut masih menggunakan software Microsoft exce/ untuk proses pengolahan data serta pengambilan keputusan. Ms. exce/juga hanya dapat berjalan di platform windows, sehingga sering terjadi masalah perbedaan platform dapat menjadi kendala bagi suatu perusahaan. Pengolahan untuk perencanaan penjualan dibuat oleh masing-masing sales man di seluruh cabang masih menggunakan data exce/ dan setiap tanggal 25 harus di submit ke kantor pusat sehingga mencangkup data yang besar.

Dalam penelitian Nur Kholis Mansur, DKK (2019) menyatakan bahwa "implementasi sistem informasi distribusi cabai yang dikembangkan memiliki manfaat untuk membantu pemerintah dalam melakukan pendataan jumlah produksi dan analisa distribusi cabai di Jawa Timur. Petani juga bisa memantau perkembangan produksi dan jumlah konsumsi cabai tiap bulan di Jawa Timur" [3]. Dan pada penelitian Merry Agustina dan Fina Oktasari (2012) bahwa dengan "menghasilkan sebuah sistem terkomputerisasi yang dapat mengolah data distribusi LPG pada PT SAK Palembang sehingga dapat membantu kelancaran proses pendistribusian karena tersedianya data dan laporan-laporan yang akurat" [4].

Penelitian ini akan merancang sistem informasi perencanaan penjualan dan distribusi di PT GMK serta serta membuat sales forecast (perencanaan penjualan) untuk mengimplementasikan kalkulasi distribution plan (perencanaan distribusi) berdasarkan stock awal dan DOI (Days Of Inventory) yang telah dibuat pada bagian sales forecast. Dimana ada penjualan yang dilakukan antara distributor dan customer (sellout) dan penjualan langsung PT GMK (sellin).

Berdasarkan pemaparan di atas, penelitian akan memfokuskan pada "Sistem Informasi Perencanaan Penjualan Dan Distribusi Barang Berbasis Web Pada PT GMK". Sehingga pada saat membuat perencanaan distribusi yang diserahkan kepada bagian gudang tidak terjadi kesalahpahaman data atas permintaan barang. Dengan demikian permintaan pelanggan yang akan lebih mendorong peningkatan penjualan serta kepuasan pelanggan baik dari sisi ketepatan watu dan tepat jumlah barang.

\section{Metode Penelitian}

Untuk pengembangan sistem penelitian ini menggunakan model SDLC (Software Development Life Cycle). SDLC adalah proses pembuatan dan pengubahan sistem serta model dan metodologi yang digunakan untuk mengembangkan sebuah sistem. Adapun model SDLC untuk penyelesaiannya memakai model waterfall. Model SDLC air terjun (waterfal) sering juga disebut model sekuensial linier atau alur hidup klasik. Model air terjun menyediakan pendekatan alur hidup perangkat lunak secara sekuensial atau terurut [5][6].

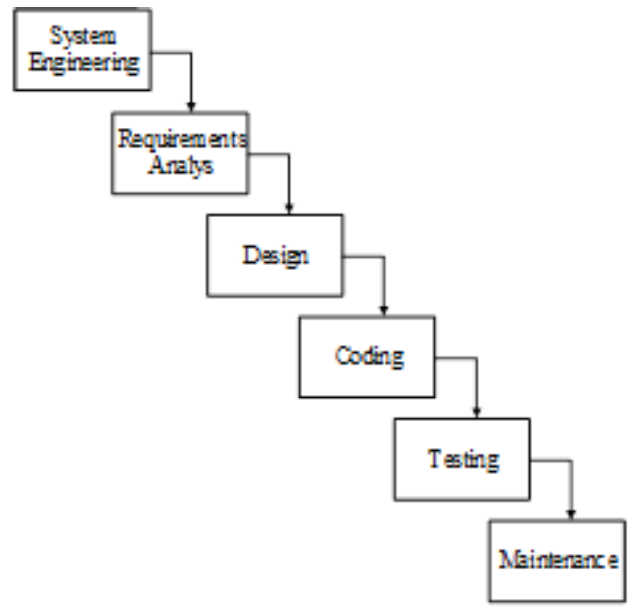

Gambar 1 Model Waterfall 


\section{Analisa Sistem Berjalan}

\section{Sales Forecast}

Analisis sistem merupakan gambaran tentang sistem yang saat ini sedang berjalan di PT Gandum Mas Kencana Tangerang pada bagian perencanaan penjualan, sistem yang digunakan masih sederhana dan konvensional yaitu dengan menggunakan Microsoft exce/ sebagai alat bantu untuk menghitung dalam perencanaan penjualan sebagai tempat menyimpan hasil pengolahan data.

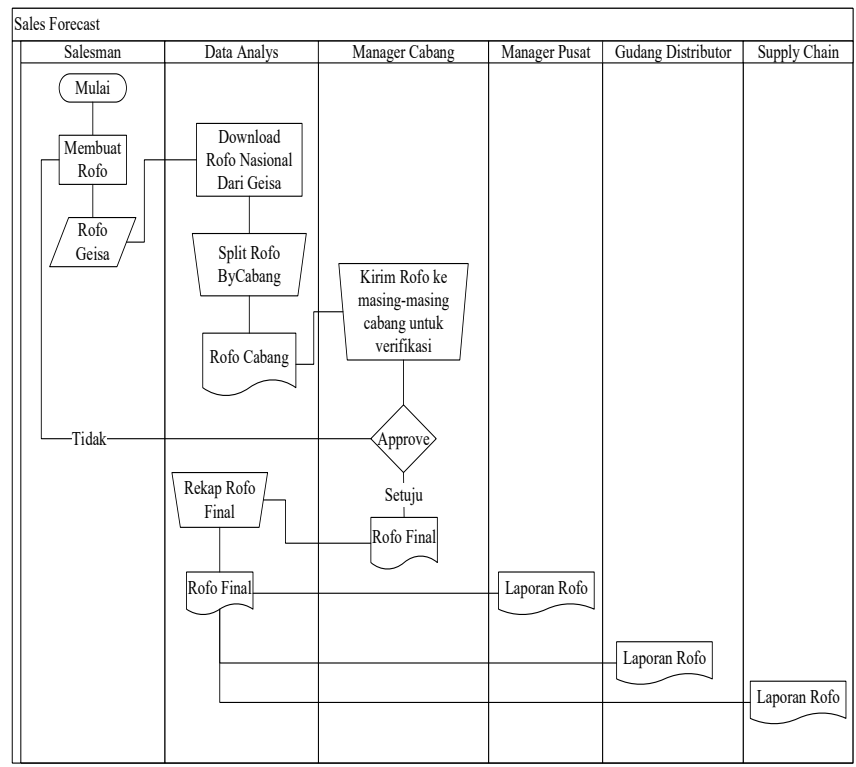

Gambar 2 Sales Forecast

\section{Distribution plan}

Dalam bagian sistem distribution plan dimana kelanjutan dari sales forecast bahwa untuk melakukan pengolah data juga masih menggunakan sistem yang manual dengan menggunakan Microsoft excel maka sering terjadi kesalahpahaman hasil pengolahan data yang akan diserahkan ke gudang distributor.

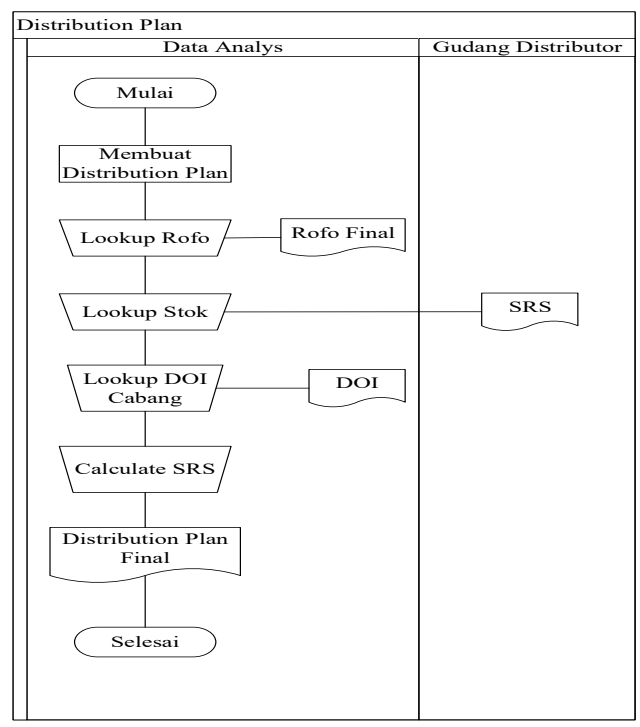

Gambar 3 Distribution plan 


\section{Analisa Sistem Yang Baru}

Dari analisa tersebut diharapkan dapat menghasilkan sebuah aplikasi yang dimana dapat membantu serta mempermudah bagi pekerja yang terlibat dalam proses bisnis di PT Gandum Mas Kencana seperti data analis, managercabang dan salesman dalam melakukan perencanaan penjualan dan distribusi barang. Unified Modeling Language (UML) adalah salah satu standar bahasa yang banyak digunakan di dunia industri untuk mendefinisikan requirement, membuat analisis dan desain, serta menggambarkan arsitektur dalam pemrograman berorientasi objek [7].

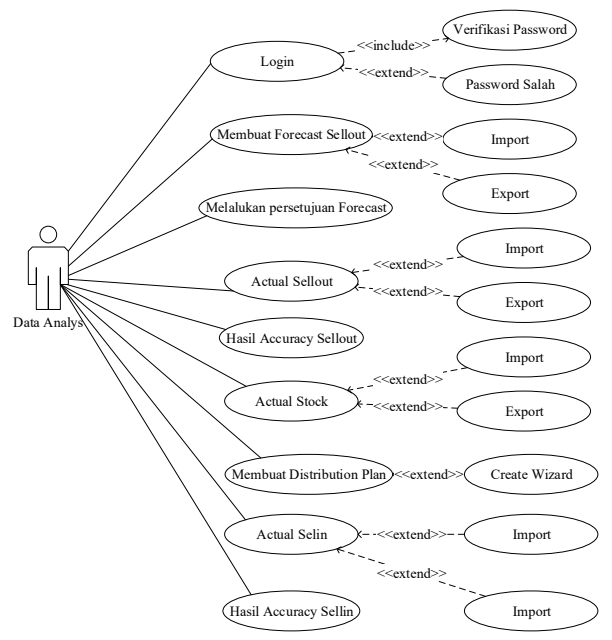

Gambar 4 Use case diagram Admin

Berdasarkan use case diagram di atas aktivitas yang dilakukan oleh Admin sebagai berikut, yaitu:

1. Admin login terlebih dahulu untuk dapat masuk ke dalam sistem.

2. Admin dapat membuka module setting, stock management, sellin management, sellout management.

3. Admin memilih module setting sebagai module tambahan, module ini dapat mengelola data distributor, employee, product, customer dan user.

4. Admin memilih module stock management, module dapat meng-input dan melihat data stock dalam periode tertentu.

5. Admin memilih module sellin management, module ini dapat mengelola data sellin dan melihat rekap data sellin berdasarkan priode tertentu. Selain itu module ini juga dapat membuat distribution plan dan melihat rekap data distribution plan yang dikelola.

6. Admin memilih module sellout management, module ini dapat mengelola data sellout dan melihat rekap data sellout berdasarkan periode tertentu. Selain itu juga module ini juga dapat mengelola persetujuan dari seluruh useryang ada dan melihat data persetujuan.

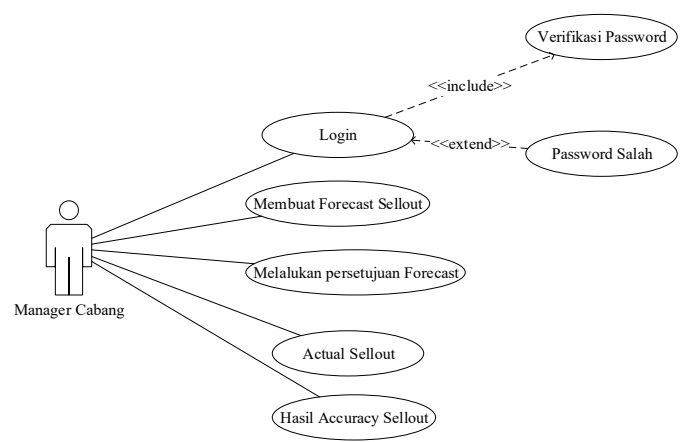

Gambar 5 Use case diagram Manager Cabang 
Berdasarkan use case diagram di atas aktivitas yang dilakukan oleh Admin sebagai berikut, yaitu:

1. Manager cabang login terlebih dahulu agar dapat masuk ke dalam sistem.

2. Manager cabang hanya memilih module sellout management, module ini dapat mengelola data sellout dan melihat rekap data sellout berdasarkan priode tertentu. Untuk membuat forecast sellout dilakukan dengan cara input data atau tidak terdapat tombol importdan export seperti yang dilakukan oleh data analyst. Selain itu juga module ini juga dapat mengelola persetujuan dari seluruh bawahannya dan melihat data persetujuan.

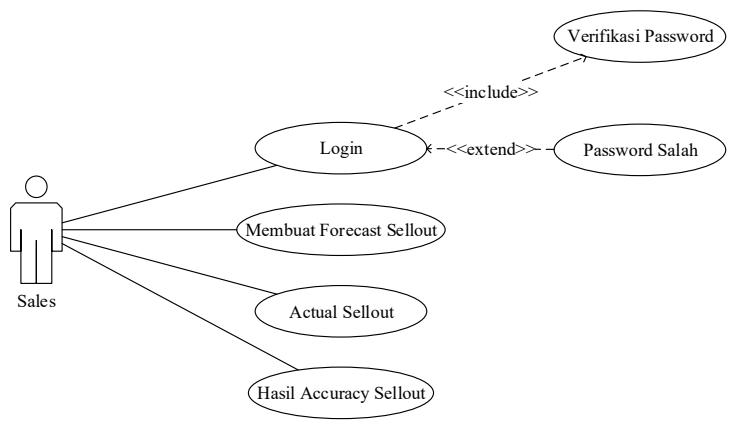

Gambar 6 Use case diagram Sales

1. Sales login terlebih dahulu agar dapat masuk ke dalam sistem.

2. Sales memilih module sellout management, module ini dapat mengelola data sellout dan melihat rekap data sellout berdasarkan priode tertentu. Untuk membuat forecast sellout dilakukan dengan cara input data atau tidak terdapat tombol import dan export seperti yang dilakukan oleh data analyst. Selain itu juga module ini melihat data persetujuan masingmasing sales.

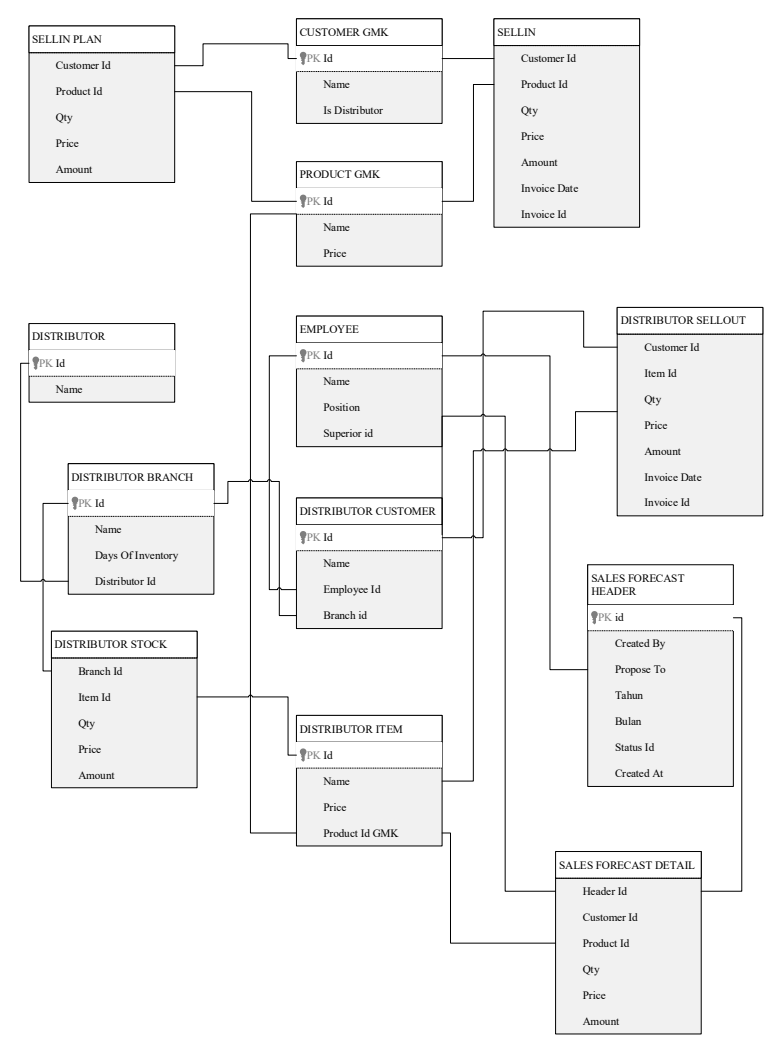

Gambar 7 Class diagram 
Jurnal TeIKa, Volume 11, Nomor 2, Oktober 2021

Class diagram (Gambar 7) menjelaskan bagaimana sistem informasi dan untuk menggambarkan grafis statik class, tipe dan hubungan keterkaitan di antara class-class yang ada di dalam sistem informasi perencanaan penjualan dan distribusi pada PT GMK. Pada tabel tersebut terdapat beberapa atribut untuk menyimpan beberapa data. Dalam sebuah tabel akan terdapat beberapa primary keydan terdapat 1 foreign key.

\section{Perhitungan Distribution plan}

Pengumpulan data rofo dan stock actual (sellout) pada bulan September - Oktober 2020. Pada bagian ini dilakukan perhitungan distribution plan yang dilakukan perusahaan. Untuk menghitung distribution plan digunakan data rofo, data stock actual (sellout) bulan September dan DOI yang telah ditetapkan dari masing-masing distributor [8]. Berikut ini contoh perhitungan distribution plan pada produk profesional chocolates dark compound 12x1 Kg bulan September dengan harga produk Rp 448.445.

Tabel 1 Distribution plan dalam quantity

\begin{tabular}{|c|c|c|c|c|c|c|c|c|}
\hline \multirow[b]{2}{*}{ branch_id } & \multirow[b]{2}{*}{ branch_name } & \multirow[b]{2}{*}{ DOI } & \multicolumn{6}{|c|}{ Qty } \\
\hline & & & $\begin{array}{c}\text { ROFO } \\
\text { SEP }\end{array}$ & $\begin{array}{c}\text { ROFO } \\
\text { OKT }\end{array}$ & $\begin{array}{c}\text { ROFO } \\
\text { NOV }\end{array}$ & $\begin{array}{r}\text { STOK } \\
\text { AWAL }\end{array}$ & $\begin{array}{c}\text { END } \\
\text { STOK } \\
\text { PLAN } \\
\end{array}$ & $\begin{array}{c}\text { DISTRIBUTION } \\
\text { PLAN } \\
\end{array}$ \\
\hline 2000 & GMK Direct & 7 & 5.586 & 5.837 & 6.418 & 0 & 0 & 5.586 \\
\hline 3113 & PK Bandung & 15 & 1.859 & 2.155 & 2.253 & 100 & 575 & 2.334 \\
\hline 3114 & PK Surabaya & 30 & 348 & 943 & 1.001 & 1.766 & 723 & -695 \\
\hline 3115 & PK Makasar & 45 & 179 & 140 & 183 & 206 & 177 & 151 \\
\hline 3116 & PK Denpasar & 30 & 242 & 198 & 230 & 584 & 152 & -190 \\
\hline 3117 & PK Semarang & 25 & 1.711 & 1.466 & 978 & 120 & 880 & 2.471 \\
\hline 3118 & PK Palembang & 30 & 644 & 622 & 721 & 199 & 477 & 922 \\
\hline 3119 & PK Cikupa & 30 & 3.591 & 3.318 & 3.687 & 1.368 & 2.544 & 4.767 \\
\hline 3120 & PK Sinarhati & 15 & 0 & 0 & 0 & 0 & 0 & 0 \\
\hline 3126 & PK Jakarta 1 & 15 & 696 & 807 & 96 & 58 & 215 & 853 \\
\hline 3127 & PK Jakarta 2 & 15 & 369 & 546 & 149 & 0 & 146 & 515 \\
\hline 3139 & PK Yogyakarta & 25 & 1.702 & 1.622 & 705 & 261 & 973 & 2.414 \\
\hline 3140 & PK Banjarmasin & 45 & 156 & 96 & 16 & 129 & 122 & 149 \\
\hline TOTAL & & & 17.083 & 17.750 & 16.437 & 4.790 & 6.983 & 19.275 \\
\hline
\end{tabular}

Tabel 2 Distribution plan dalam value (Rupiah)

\begin{tabular}{|c|c|c|c|}
\hline \multicolumn{5}{|c|}{ Value } \\
\hline ROFO & STOK AWAL & END STOK PLAN & DISTRIBUTION PLAN \\
\hline 2.505 .016 .309 & 0 & 0 & 2.505 .016 .309 \\
\hline 833.660 .100 & 44.844 .562 & 257.706 .655 & 1.046 .522 .193 \\
\hline 156.059 .018 & 792.066 .957 & 324.211 .115 & -311.796 .823 \\
\hline 80.271 .736 & 92.155 .595 & 79.524 .327 & 67.640 .469 \\
\hline 108.523 .800 & 261.892 .153 & 68.074 .020 & -85.294 .333 \\
\hline 767.290 .173 & 53.813 .511 & 394.452 .622 & 1.107 .929 .284 \\
\hline 288.798 .873 & 89.016 .517 & 213.848 .689 & 413.631 .045 \\
\hline
\end{tabular}




\begin{tabular}{|c|c|c|c|}
\hline 1.610 .367 .627 & 613.473 .477 & 1.140 .755 .547 & 2.137 .649 .698 \\
\hline 0 & 34 & 0 & -34 \\
\hline 312.118 .036 & 26.009 .886 & 96.505 .462 & 382.613 .612 \\
\hline 165.476 .373 & 15 & 65.293 .658 & 230.770 .016 \\
\hline 763.254 .164 & 117.044 .286 & 436.427 .116 & 1.082 .636 .995 \\
\hline 69.957 .491 & 57.849 .464 & 54.530 .967 & 66.638 .994 \\
\hline 7.660 .793 .701 & 2.148 .166 .455 & 3.131 .330 .179 & 8.643 .957 .425 \\
\hline
\end{tabular}

Adapun awal untuk melakukan perhitungan end stock plan dalam quantity, maka harus menentukan standard formula yang telah ditetapkan. Formulasi untuk menghitung End stock plan (qty) adalah:

$$
\mathrm{ESP}=\text { Rofo(Oktober) } / 30 \times(\text { DOI-7) }
$$

Contoh menghitung End stock plan (qty) pada PK Bandung adalah:

$$
\begin{aligned}
\mathrm{ESP} & =2155 / 30 \times(15-7) \\
& =575 \text { qty }
\end{aligned}
$$

\section{Catatan:}

Setiap Rofo yang dihitung berdasarkan rofo bulan berikutnya

Untuk 30 diperoleh melalui produk yang dihitung dalam per hari

Untuk 7 diperoleh melalui penutupan PO pada tanggal 24 untuk bulan berikutnya ke tanggal 1

Formulasi untuk menghitung Distribution plan (qty) adalah:

$$
\begin{aligned}
& \mathrm{DP}=\mathrm{ESP}+\text { Rofo(Sept)-SA } \\
& \mathrm{DP}=\text { Distribution plan } \\
& \mathrm{ESP}=\text { End stock plan } \\
& \mathrm{SA}=\text { Stock Awal }
\end{aligned}
$$

Contoh menghitung Distribution plan (qty) pada PK Bandung adalah:

$$
\begin{aligned}
\mathrm{DP} & =575+1.859-100 \\
& =2.235
\end{aligned}
$$

Untuk melakukan perhitungan dalam value (rupiah) dilakukan dengan masing-masing tiap tabel seperti Rofo (September), Stok Awal, End stock plan dan Distribution plan di kali(x) dengan harga produk. Contoh menghitung Rofo Sept dalam value (rupiah) pada PK Bandung adalah:

$$
\begin{aligned}
& R O F O=1.859 \times 448.445 \\
& =\mathrm{Rp} 883.660 .100 \\
& \mathrm{SA}=100 \times 448.445 \\
& =\operatorname{Rp} 44.844 .562 \\
& \mathrm{ESP}=575 \times 448.445 \\
& =\operatorname{Rp} 257.706 .655 \\
& \mathrm{DP}=2.334 \times 448.445 \\
& =\operatorname{Rp} 1.046 .522 .193
\end{aligned}
$$


Hasil akhir dari total perhitungan selengkapnya pada produk professional chocolates dark compound $12 \times 1 \mathrm{Kg}$ bulan September disajikan pada tabel 1 dan tabel 2 di atas. Dalam menghitung distribution plan pada seluruh produk di PT. GMK dilakukan dengan formula yang telah paparkan di atas.

\section{Hasil}

Dalam proses pengembangan sistem informasi yang diharapkan dengan tujuan yang akurat untuk membantu proses operasional pada PT Gandum Mas Kencana Tangerang agar berjalan lancar. Interface Program yang dihasilkan dari perancangan sebagai berikut:

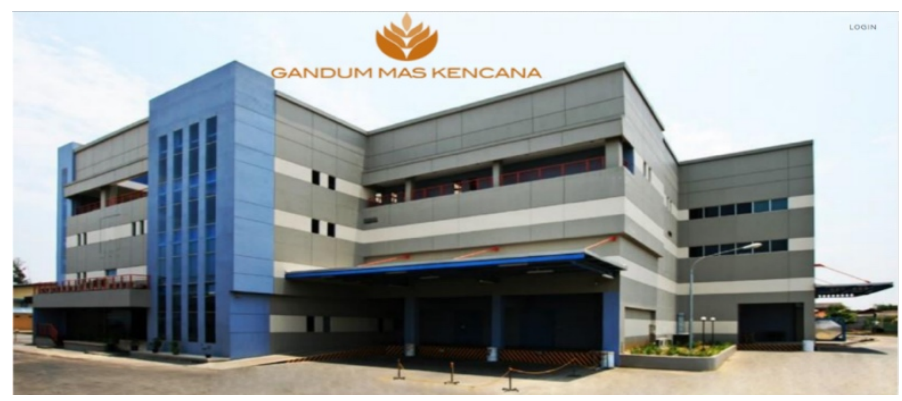

Gambar 8 Halaman Landing

Halaman landing (Gambar 6) menjelaskan saat user mengetikkan url (alamat web aplikasi), dimana isi tampilan ini adalah gambar dari gedung perkantoran (gedung K) PT Gandum Mas Kencana Tangerang. Pada tampilan ini juga terdapat tombol login.

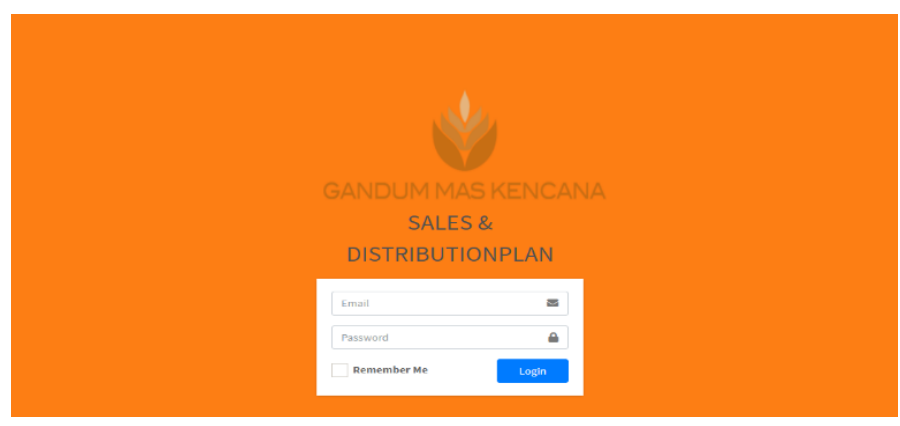

Gambar 9 Halaman Login

Halaman login (Gambar 7) menjelaskan saat user menekan tombol login pada halaman landing, dimana isi tampilan login untuk memasukkan usemame (email) dan password yang telah terdaftar pada sistem pada masing-masing user.

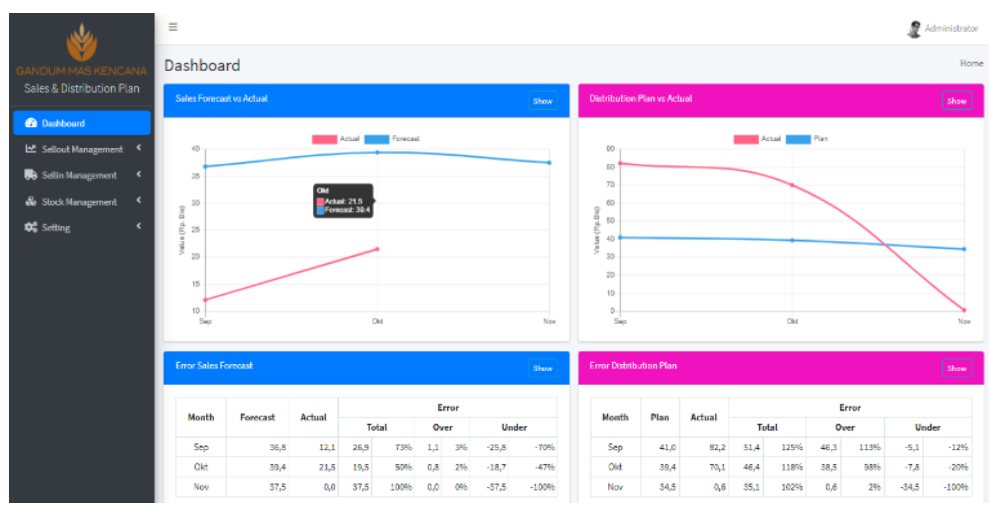

Gambar 10 Halaman Home (Dashboard) 
Pada saat user sebagai admin sudah melewati tahap login, maka halamam pertama yang muncul setelah login adalah halaman dashboard (Gambar 8). Dimana pada halaman dashboard ini menampilkan grafik perbandingan antara sales forecast dengan actual dan juga distribution plan dengan actual secara nasional. Adapun tampilan error sales forecast dan error distribution plan dalam periodenya secara nasional grafik.
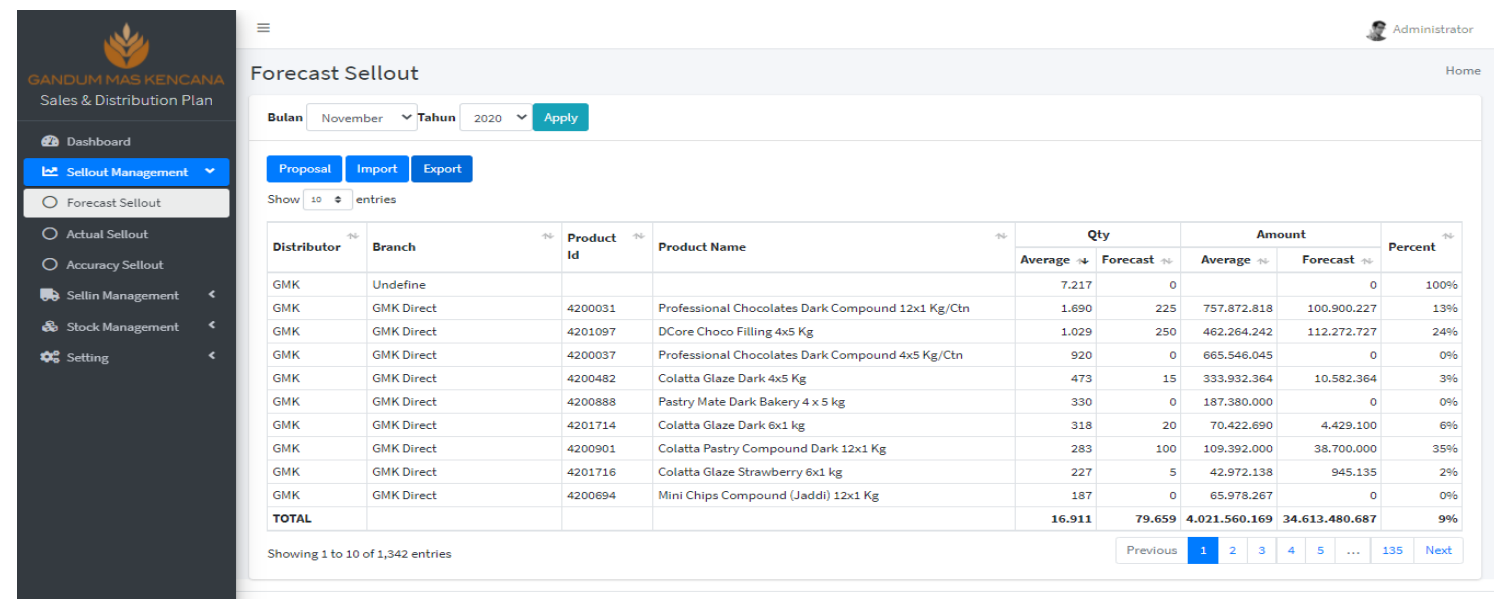

Gambar 11 Halaman Forecast Sellout

Halaman ini (Gambar9) merupakan halaman yang menampilkan forecast yang telah di import. Pada halaman ini juga mencatat secara otomatis forecast dalam periode tertentu.
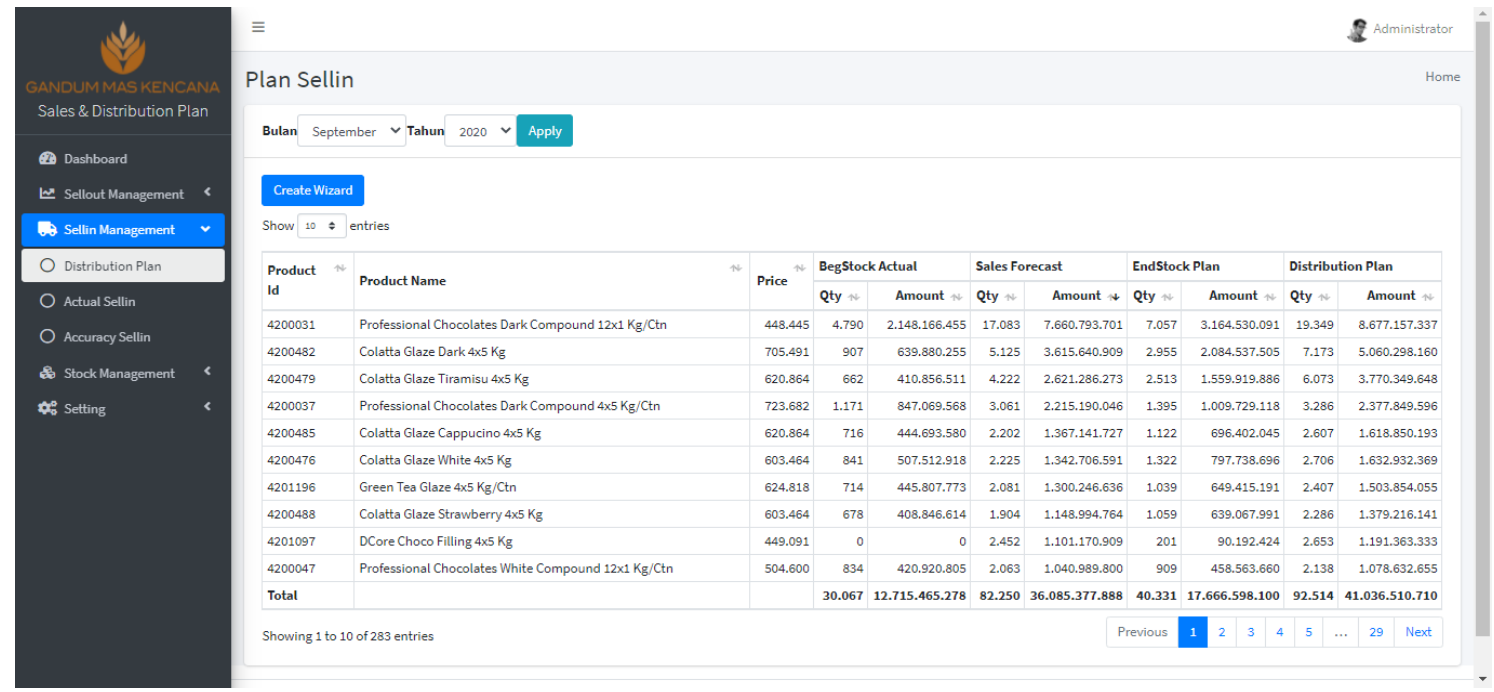

\section{Gambar 12 Halaman Distribution plan}

Halaman ini (Gambar 10) menjelaskan halaman yang menampilkan hasil kalkuklasi distribution plan yang telah di create. Pada halaman ini juga mencatat secara otomatis distribution plan dalam periode tertentu. 


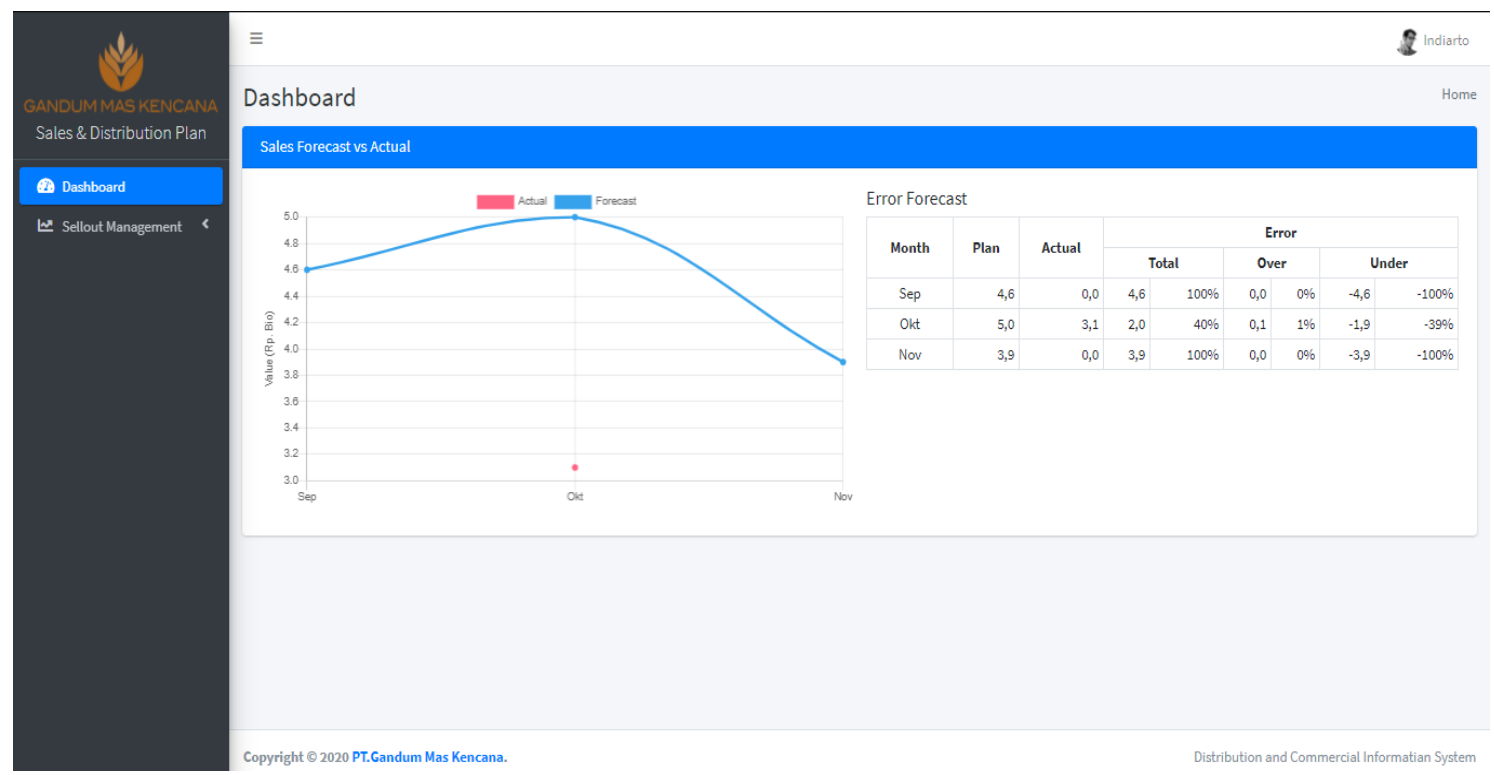

Gambar 13 Halaman Home (Sales man \& Manager Cabang)

Pada saat user login sebagai manager cabang dan sales man sudah melewati tahap login, maka halamam pertama yang muncul setelah login adalah halaman dashboard (Gambar 11). Dimana pada halaman dashboard ini menampilkan grafik perbandingan antara sales forecast dengan actual yang dibuat oleh masing-masing user. Adapun module sellout management yang dimana halaman tampilan tersebut sama seperti halama tampilan sebagai admin hanya saja ada perbedaan dalam data. Data yang ada hanya input dilakukan oleh masing-masing usemya. Untuk login sebagai manager cabang dapat melakukan persetujuan sedangkan jika login sebagai sales man tidak dapat melakukan persetujuan proposal.

\section{Hasil Pengujian}

Dalam pengujian sistem akan dilakukan untuk mengetahui apakah sistem telah berjalan dengan yang diharapkan. Tujuan pengujian sistem adalah untuk mengetahui apakah fungsi berjalan dengan lancar dan juga kelemahan dari fungsi yang diharapkan pada sistem ini. Metode yang digunakan penulis adalah metode black box testing. "Metode black box testing adalah sebuah metode yang dipakai untuk menguji sebuah software tanpa harus memperhatikan detail software. Pengujian ini hanya memeriksa nilai keluaran berdasarkan nilai masukan masing-masing. Tidak ada upaya untuk mengetahui kode program apa yang output pakai" [9].

Tabel 3 Hasil Pengujian Sistem (Admin)

\begin{tabular}{|c|c|c|c|c|}
\hline No & $\begin{array}{c}\text { Komponen Sistem Yang di } \\
\text { Uij }\end{array}$ & Skenario Uji & Hasil Yang di Harapkan & Jenis Penguji \\
\hline \multirow{2}{*}{1} & \multirow{2}{*}{ Halaman Login } & $\begin{array}{l}\text { Masukkan data } \\
\text { username dan password } \\
\text { yang benar. }\end{array}$ & $\begin{array}{l}\text { Saat user memasukkan data, maka } \\
\text { akan masuk ke halaman home } \\
\text { (dashboard). }\end{array}$ & $\begin{array}{l}\text { [ }] \text { Diterima } \\
{[\quad] \text { Ditolak }}\end{array}$ \\
\hline & & $\begin{array}{l}\text { Memasukkan data } \\
\text { username dan password } \\
\text { yang salah. }\end{array}$ & $\begin{array}{l}\text { Saat user memasukkan data, maka } \\
\text { akan kembali kembali ke halaman } \\
\text { login. }\end{array}$ & $\begin{array}{l}\text { [ } \text { ] Diterima } \\
\text { [ ] Ditolak }\end{array}$ \\
\hline 2 & Halaman Home (Dashboard) & res & $\begin{array}{l}\text { Saat user membuka halaman } \\
\text { dashboard, maka akan } \\
\text { menampilkan grafik dan tabel error } \\
\text { untuk hasil akhir sales forecast dan } \\
\text { distribution plan. }\end{array}$ & $\begin{array}{l}\text { [ } \text { ] Diterima } \\
\text { [ ] Ditolak }\end{array}$ \\
\hline 3 & Halaman Forecast Sellout & - & $\begin{array}{l}\text { Saat user membuka halaman } \\
\text { forecast sellout, maka akan } \\
\text { menampilkan data forecast yang } \\
\text { ada }\end{array}$ & $\begin{array}{l}\text { [ } \text { ] Diterima } \\
\text { [ ] Ditolak }\end{array}$ \\
\hline
\end{tabular}




\begin{tabular}{|c|c|c|c|c|}
\hline 4 & $\begin{array}{c}\text { Halaman Import Forecast } \\
\text { Sellout }\end{array}$ & $\begin{array}{lr}\text { Meng-upload r data } \\
\text { forecast dalam bentuk } \\
\text { excel. }\end{array}$ & $\begin{array}{l}\text { Setelah user memasukkan semua } \\
\text { data, sistem akan kembali ke } \\
\text { halaman forecast sellout. }\end{array}$ & $\begin{array}{l}\text { [ } \text { ] Diterima } \\
\text { [ ] Ditolak }\end{array}$ \\
\hline 5 & Halaman Proposal & - & $\begin{array}{l}\text { Saat user membuka halamaan } \\
\text { proposal, maka akan menampilkan } \\
\text { nama-nama orang yang membuat } \\
\text { forecast. }\end{array}$ & 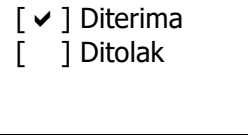 \\
\hline 6 & Halaman Actual Sellout & $\cdot$ & $\begin{array}{l}\text { Saat user membuka halaman } \\
\text { actual sellout, sistem akan } \\
\text { menampilkan data produk untuk } \\
\text { actual sellout dalam periode } \\
\text { tertentu. }\end{array}$ & $\begin{array}{l}\text { [ } \text { ] Diterima } \\
{[\quad] \text { Ditolak }}\end{array}$ \\
\hline 7 & $\begin{array}{c}\text { Halaman Import Actual } \\
\text { Sellout }\end{array}$ & $\begin{array}{l}\text { Mengupload data actual } \\
\text { sellout dalam bentuk } \\
\text { excel. }\end{array}$ & $\begin{array}{l}\text { Setelah user memasukkan semua } \\
\text { data, sistem akan kembali ke } \\
\text { halaman actual sellout. }\end{array}$ & $\begin{array}{l}\text { [ } \text { ] Diterima } \\
{[\quad] \text { Ditolak }}\end{array}$ \\
\hline 8 & Halaman Accuracy Sellout & - & $\begin{array}{l}\text { Saat user membuka halaman } \\
\text { accuracy sellout, maka akan } \\
\text { menampilkan data produk dan hasil } \\
\text { akurasi sellout dalam periode } \\
\text { tertentu. }\end{array}$ & $\begin{array}{l}\text { [ } \text { ] Diterima } \\
{[\quad] \text { Ditolak }}\end{array}$ \\
\hline 9 & Halaman Actual Begin Stock & . & $\begin{array}{l}\text { Setelah user membuka halaman } \\
\text { actual begin stock, maka sistem } \\
\text { menampilkan data produk untuk } \\
\text { actual begin stock dalam periode } \\
\text { tertentu. }\end{array}$ & $\begin{array}{l}\text { [ } \text { ] Diterima } \\
\text { [ ] Ditolak }\end{array}$ \\
\hline 10 & $\begin{array}{c}\text { Halaman Import Actual Begin } \\
\text { Stock }\end{array}$ & $\begin{array}{l}\text { Mengupload data actual } \\
\text { begin stock dalam } \\
\text { bentuk excel. }\end{array}$ & $\begin{array}{l}\text { Setelah user memasukkan semua } \\
\text { data, sistem akan kembali ke } \\
\text { halaman actual begin stock. }\end{array}$ & $\begin{array}{l}\text { [ } \checkmark \text { ] Diterima } \\
{[\quad] \text { Ditolak }}\end{array}$ \\
\hline 11 & Halaman Distribution plan & - & $\begin{array}{l}\text { Saat user membuka halamaan } \\
\text { distribution plan, maka akan } \\
\text { menampilkan data produk dan hasil } \\
\text { perhitungan distribution plan dalam } \\
\text { periode tertentu. }\end{array}$ & $\begin{array}{l}\text { [ } \text { ] Diterima } \\
\text { [ ] Ditolak }\end{array}$ \\
\hline 12 & $\begin{array}{c}\text { Halaman Create Distribution } \\
\text { plan }\end{array}$ & $\begin{array}{l}\text { Membuat distribution } \\
\text { plan. }\end{array}$ & $\begin{array}{l}\text { Setelah user memasukkan semua } \\
\text { data, sistem akan kembali ke } \\
\text { halaman distribution plan }\end{array}$ & $\begin{array}{l}\text { [ひ ] Diterima } \\
{[\text { ] Ditolak }}\end{array}$ \\
\hline 13 & Halaman Actual Sellin & 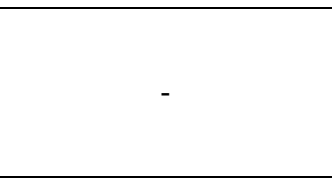 & $\begin{array}{l}\text { Saat user membuka halaman } \\
\text { actual sellin, sistem akan } \\
\text { menampilkan data produk untuk } \\
\text { actual sellin dalam periode } \\
\text { tertentu. }\end{array}$ & $\begin{array}{l}\text { [マ] Diterima } \\
{[\text { ] Ditolak }}\end{array}$ \\
\hline 14 & Halaman Import Actual Sellin & $\begin{array}{l}\text { Mengupload data actual } \\
\text { sellin dalam bentuk } \\
\text { excel. }\end{array}$ & $\begin{array}{l}\text { Setelah user memasukkan semua } \\
\text { data, sistem akan kembali ke } \\
\text { halaman actual sellin. }\end{array}$ & $\begin{array}{l}\text { [レ ] Diterima } \\
{[\text { [ ] Ditolak }}\end{array}$ \\
\hline 15 & Halaman Accuracy Sellin & ( & $\begin{array}{l}\text { Saat user membuka halaman } \\
\text { accuracy sellin, maka akan } \\
\text { menampilkan data produk dan hasil } \\
\text { akurasi sellin dalam periode } \\
\text { tertentu. }\end{array}$ & $\begin{array}{l}\text { [ } \text { ] Diterima } \\
{[\text { ] Ditolak }}\end{array}$ \\
\hline 16 & Halaman Product & - & $\begin{array}{l}\text { Saat pengguna membuka halaman } \\
\text { product, maka akan menampilkan } \\
\text { data product atau master data. }\end{array}$ & $\begin{array}{l}\text { [マ] Diterima } \\
{[\text { ] Ditolak }}\end{array}$ \\
\hline 17 & Halaman Create Product & $\begin{array}{l}\text { Memasukkan id, nama } \\
\text { product dan harga untuk } \\
\text { dijadikan sebagai master } \\
\text { data. }\end{array}$ & $\begin{array}{l}\text { Saat user memasukkan semua } \\
\text { data, sistem akan kembali ke } \\
\text { halaman product. }\end{array}$ & $\begin{array}{l}\text { [マ ] Diterima } \\
{[\text { ] Ditolak }}\end{array}$ \\
\hline 18 & Halaman Customer & 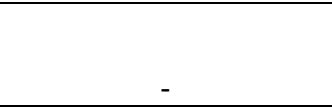 & $\begin{array}{l}\text { Saat pengguna membuka halaman } \\
\text { customer, maka akan menampilkan } \\
\text { data customer atau master data. }\end{array}$ & $\begin{array}{l}\text { [ひ ] Diterima } \\
{[\text { ] Ditolak }}\end{array}$ \\
\hline
\end{tabular}




\begin{tabular}{|c|c|c|c|c|}
\hline 19 & Halaman Create Customer & $\begin{array}{l}\text { Memasukkan id, nama } \\
\text { customer dan pilihan } \\
\text { direct untuk dijadikan } \\
\text { sebagai master data. }\end{array}$ & $\begin{array}{l}\text { Saat user memasukkan semua } \\
\text { data, sistem akan kembali ke } \\
\text { halaman customer. }\end{array}$ & $\begin{array}{l}\text { [ }] \text { Diterima } \\
{[\text { ] Ditolak }}\end{array}$ \\
\hline 20 & Halaman Employee & ${ }^{2}$ & $\begin{array}{l}\text { Saat pengguna membuka halaman } \\
\text { employee maka akan } \\
\text { menampilkan data employee atau } \\
\text { master data. }\end{array}$ & $\begin{array}{l}\text { [ }] \text { ] Diterima } \\
{[\text { ] Ditolak }}\end{array}$ \\
\hline 21 & Halaman Create Employee & $\begin{array}{l}\text { Memasukkan id, nama } \\
\text { employee, job position } \\
\text { dan report to (atasan) } \\
\text { untuk dijadikan sebagai } \\
\text { master data. }\end{array}$ & $\begin{array}{l}\text { Saat user memasukkan semua } \\
\text { data, sistem akan kembali ke } \\
\text { halaman employee. }\end{array}$ & $\begin{array}{l}\text { [ } \text { ] Diterima } \\
\text { [ ] Ditolak }\end{array}$ \\
\hline 22 & Halaman Distributor & - & $\begin{array}{l}\text { Saat pengguna membuka halaman } \\
\text { distributor, maka akan } \\
\text { menampilkan data distributor atau } \\
\text { master data. }\end{array}$ & $\begin{array}{l}\text { [` ] Diterima } \\
\text { [ ] Ditolak }\end{array}$ \\
\hline 23 & Halaman Create Distributor & $\begin{array}{l}\text { Memasukkan id, nama } \\
\text { distributor dan aksi } \\
\text { lainnya dijadikan sebagai } \\
\text { master data. }\end{array}$ & $\begin{array}{l}\text { Saat user memasukkan semua } \\
\text { data, sistem akan kembali ke } \\
\text { halaman distributor. }\end{array}$ & $\begin{array}{l}\text { [マ] Diterima } \\
{[\quad] \text { Ditolak }}\end{array}$ \\
\hline 24 & Halaman User & 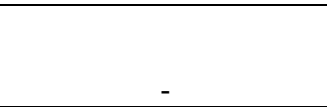 & $\begin{array}{l}\text { Saat pengguna membuka halaman } \\
\text { user, maka akan menampilkan data } \\
\text { user atau master data. }\end{array}$ & $\begin{array}{l}\text { [ }] \text { Diterima } \\
{[\quad] \text { Ditolak }}\end{array}$ \\
\hline 25 & Halaman Create User & $\begin{array}{l}\text { Memasukkan id, nama } \\
\text { user, email, } \\
\text { role,employee dan active } \\
\text { atau tidaknya untuk } \\
\text { dijadikan sebagai master } \\
\text { data. }\end{array}$ & $\begin{array}{l}\text { Saat admin memasukkan semua } \\
\text { data, sistem akan kembali ke } \\
\text { halaman user. }\end{array}$ & $\begin{array}{l}\text { [ }] \text { Diterima } \\
{[\text { ] Ditolak }}\end{array}$ \\
\hline 26 & Logout & $\begin{array}{l}\text { Admin menekan tombol } \\
\text { logout yang terdapat } \\
\text { pada menu slidebar web } \\
\text { aplikasi. }\end{array}$ & $\begin{array}{l}\text { Saat admin menekan tombol, maka } \\
\text { sistem akan kembali ke halaman } \\
\text { login. }\end{array}$ & $\begin{array}{l}\text { [ }] \text { Diterima } \\
{[\quad] \text { Ditolak }}\end{array}$ \\
\hline
\end{tabular}

Tabel 4 Hasil Pengujian Sistem (Sales man \& Manager Cabang)

\begin{tabular}{|c|c|c|c|c|}
\hline No & Komponen Sistem Yang di Uji & Skenario Uji & Hasil Yang di Harapkan & Jenis Penguj $\mathrm{i}$ \\
\hline 1 & Halaman Home (Dashboard) & - & $\begin{array}{l}\text { Saat user membuka } \\
\text { halaman dashboard, maka } \\
\text { akan menampilkan grafik } \\
\text { dan tabel eror untuk hasil } \\
\text { akhir sales forecast. }\end{array}$ & $\begin{array}{l}\text { [ } \text { ] Diterima } \\
\text { [ ] Ditolak }\end{array}$ \\
\hline 2 & Halaman Selloutt Management & - & $\begin{array}{l}\text { Saat user menekan sellout } \\
\text { management, maka akan } \\
\text { menampilkan halaman } \\
\text { forecast sellout, actual } \\
\text { sellout dan accuracy sellout. }\end{array}$ & $\begin{array}{l}\text { [ } \text { ] Diterima } \\
\text { [ ] Ditolak }\end{array}$ \\
\hline
\end{tabular}

Berdasarkan dari hasil penguji sistem di atas, maka penulis dapat menyimpulkan bahwa sistem sudah berjalan dengan lancar sesuai dengan fungsinya dan menghasilkan informasi yang diharapkan sesuai dengan hasil data yang ada dan tersimpan. 


\section{Kesimpulan dan Saran}

\section{Kesimpulan}

Setelah menyelesaikan perancangan sistem perencanaan penjualan dan distribusi barang di PT Gandum Mas Kencana Tangerang penulis dapat mengambil beberapa kesimpulan sebagai berikut:

1. PT Gandum Mas Kencana Tangerang yang masih menggunakan sistem konvensional (manual) dalam kegiatan ekonominya, termasuk penghitungan dan pencatatan dalam setiap melakukan perencanaan distribusi. Hal tersebut dapat berdampak negatif pada perusahaan karena menggunakan sistem manual berisiko terjadinya human error, yaitu kesalahan penghitungan dan pencatatan. Hasil informasi yang didapat kurang relevan dan akurat sehingga kinerja pada perusahaan juga kurang efisien.

2. Sistem ini dibangun mempunyai dua bagian yaitu Front End dan Back End, dimana halaman fron end berisi menu yang bisa diakses oleh masing-masing user seperti sales man dan manager cabang tetapi usertidak dapat mengedit atau menghapus konten yang ada di website, sedangkan halaman back end dimana halaman tersebut untuk administrator (data analyst) dalam mengolah semua isi website tersebut.

3. Sistem yang dibangun menggunakan formulasi yang dijadikan acuan dalam mengkalkulasikan distribution plan pada aplikasi ini dan total hasil akhir ditampilkan pada halaman website.

\section{Saran}

Adapun saran peneliti terhadap perusahaan dan juga terhadap pengembangan penelitian ke depannya adalah sebagai berikut

1. Peneliti menyarankan agar PT Gandum Mas Kencana Tangerang segera mengganti sistem manual ke sistem informasi berbasis web agar masalah-masalah yang ada dapat teratasi.

2. Peneliti menyarankan sistem informasi ini dapat dikembangkan untuk sebagian sistem ini masih dalam melakukan import exce/karena sistem ini tidak dapat terkoneksi dengan server PT Gandum Mas Kencana Tangerang, maka perlu adanya pengembangan untuk mengubah sistem tidak lagi dengan import tetapi bisa dilakukan menghubungkan data secara real time pada web melalui server PT Gandum Mas Kencana Tangerang.

3. Peneliti menyarankan agar ke depannya aplikasi yang dibangun sudah dibahas dari segi keamanan system itu sendiri, mengingat data yang dimasukan adalah data yang krusial dan rahasia.

5. Peneliti juga menyarankan agar PT Gandum Mas Kencana Tangerang melakukan pelatihan pada pekerja yang nantinya akan menjadi user atau pengguna sistem yang baru agar menguasai sistem dengan baik.

\section{Referensi}

[1] J. I. Sihotang, "Contribution of Information Technology Capital Expenditure Towards PT Indosat Tbk. Revenue", jiscse, vol. 1, no. 4, Jan. 2016.

[2] Mildawati, T. (2000). Teknologi Informasi Dan Perkembangannya Di Indonesia. Ekuitas, Vol.4 No.2, 101.

[3] Mansur, N. K., Bukhori, S., \& Juwita, O. (2019). Sistem Informasi Distribusi Cabai Dengan Metode Distribution Requirements Planning (DRP) di Provinsi Jawa Timur. Informatics Journal, Volume. 4 No. $1,20$.

[4] Agustina, M., \& Oktasari, F. (2012). Penerapan Metode DRP (Distribusi Requirement Planning) Pada Sistem Informasi Distribusi LPG . Seminar Nasional Informatika, 76-81. 
[5] Rahmawati, E., \& Wijianto, R. (2019). Penerapan Model Waterfall Pada Pengembangan Sistem Informasi Rekam Medis Klinik Rawat Inap Naja Shafana Purwokerto. Jurnal Pilar Nusa Mandiri, Volume 15, No.1, 55.

[6] Van Casteren, Wilfred. (2017). The Waterfall Model and the Agile Methodologies : A comparison by project characteristics. 10.13140/RG.2.2.36825.72805.

[7] Wira, D., Putra, T., \& Andriani, R. (2019). Unified Modelling Language (UML) dalam Perancangan Sistem Informasi Permohonan Pembayaran Restitusi SPPD. Jurnal Teknoif, 33.

[8] Pangestu, Y. (2017). Implementasi Distribution Requirement Planning Pada PT. Arga Boga Cemerlang Surabaya. Jurnal Ilmiah Mahasiswa Universitas Surabaya, Vol. 6 No.2, 898.

[9] Cahya, Fadhila N., \& DKK. (2019). Pengujian Black Box Pada Aplikasi Sistem Seleksi Sales Terbaik Menggunakan Teknik Equivalence Partitions. Jurnal Informatika, Volume 4 No.4, 127-129.

[10] Jaya, Tri. (2018). Pengujian Aplikasi dengan Metode Blackbox Testing Boundary Value Analysis (Studi Kasus: Kantor Digital Politeknik Negeri Lampung). 10.30591/jpit.v3i1.647. 